\title{
Omnichannel Customer Experience and Technological Evolvement in Retail
}

\author{
Su Yun Bae* and Deborah G Wooldridge \\ Family and Consumer Sciences, Bowling Green State University, USA
}

*Corresponding author: Su Yun Bae, Assistant Professor, Family and Consumer

Sciences, Bowling Green State University, Bowling Green, Ohio, USA.

Received Date: January 29, 2020

Published Date: February 03, 2020

\begin{abstract}
Technological advancement is taking companies to the next level of retailing. Powered by Artificial Intelligence (AI) and integrated technological platforms, retailing poses the great potential for improvement and excellent customer experience in the omnichannel retail landscape. Retail is evolving, adapting, and transforming. Many top retailers have been making transitions in their business processes and operations in order to provide seamless and integrated customer experiences across different channels. Technologies have been implemented in physical stores to offer the benefits of online shopping. Online retailers have been also developing various ways to accommodate challenges of online shopping. Retail technologies play a pivotal role in transforming fragmented retail processes into seamlessly integrated omnichannel operations. This paper discusses the role of AI in this new retail landscape and different types of technologies that support omnichannel retailing.
\end{abstract}

\section{Introduction}

As soon as the media announced numerous retail closures and bankruptcies, people started to believe that retail is dying. However, the reality is that the current retail landscape is evolving at a fast pace and requires innovative business models to succeed. Companies need to be equipped with advanced technologies and stay informed of evolving industry and consumer trends in this new retail environment. Online shopping has affected the dynamics of omnichannel retail, and technological advancement is taking retail to the next level. Technology companies from corporations and medium-sized firms to startup companies support retail business and customer engagement.

Artificial Intelligence (AI) implies significant importance on the future of retail and evolvement in store performance and customer experience. The focus of $\mathrm{AI}$ is to establish computational intelligence in systems that think and act like a human in various business activities such as learning, reasoning, making decisions, understandingproblems and finding solutions, and other human-like abilities [1]. AI inspires every aspect of omnichannel retail through its first-party consumer data, AI-driven product recommendations, in-store operational issues, better visual merchandising, consumerbased $\mathrm{AI}$ insights, pricing and promotional suggestions, and many more. Omnichannel is the future of retail although many companies have experienced cultural challenges to transform its business model that suit the shopping needs of today's consumers. The real challenge for a retailer, however, is taking the steps to differentiate its omnichannel customer experience while remaining true to its identity and brand promise [2].

Given the importance of business transformation suited for omnichannel retail practices and technological adoption, this paper reviews a set of retail technologies that support omnichannel retailing and customer experience.

\section{Discussion}

Traditional brick-and-mortar retailers like Walmart and Target have been progressively expanding its online presence and implementing strategies to win customers and drive in-store and online traffic. Meanwhile, digitally native online retailers like Amazon and Bonobos started to open its brick-and-mortar stores in major cities to join the omnichannel trend. Omnichannel is a retail concept that offers online and offline shopping benefits in a seamless manner across different channels. AI and other related technologies support omnichannel retail practices and enhance customer shopping experiences. Some of the technologies help physical stores embrace the benefits of online shopping and support online stores to overcome its own drawbacks that can be easily 
improved at physical stores. In the first part, this paper discusses the pivotal role of brick-and-mortar stores along with supporting technologies in the omnichannel retail landscape. Next, technology companies have developed solutions that soothe the difficulties of online shopping. Some of the key evolutions are introduced in the section.

\section{Future of brick-and-mortar stores and in-store technology}

The traditional way of retailing has been challenged as e-commerce has become increasingly popular. However, it is not correct to say that online channels are overtaking brick-and-mortar stores. Traditional commerce still generates more than $90 \%$ of total retail sales despite the rapid growth of online sales. Physical store operations are the integral part of retailing, and this is evidenced by major pure-play online retailers strategically opening up offline stores although these retailers have their own way of store development and operations. The future of brick-and-mortar stores will be driven by rich consumer data and innovative in-store technologies. Although not every digitally native retailer is superior in technological advancement, key online retailers like Amazon has already adopted computer vision technology in its physical stores. Traditional brick-and-mortar stores have been slow to adopting technologies in their physical locations compared to digital natives. In-store technologies have great potential to contribute to the future of brick-and-mortar stores and retail profitability.

According to the report of CB4 (nd) [3] retail companies suffer the loss of three to five percent from total sales revenue due to store operational issues. An important key to success for in store operations is to optimize merchandising planning, buying, store allocation, replenishment, and inventory management. Powered by $\mathrm{AI}$ and data analytics, retailers can calculate projected demand at a location, day, or item-level up to several months in advance. Such technology supports retailers to enhance their competitiveness through an integrated and sophisticated planning platform [4]. It also helps maximize profits by identifying products with higher and consistent sell through at minimized discount rate. Radio frequency identification (RFID) is an item level technology that supports inventory tracking, demand forecasting, and better customer experience. By collecting real-time and accurate inventory data at the store level, RFID helps with stockout issues, replenishment productivity, and faster checkouts.

Rebecca Minkoff is one of the major brands that adopt technological innovations in its retail stores. Smart fitting rooms and interactive displays are an example of in-store technology that the brand has implemented to increase customer engagement. This technology can significantly increase sales by supporting cross and up selling strategies and making fitting room experiences much more enjoyable and convenient. Together with RFID tags and IoT technology, smart fitting rooms generate consumer data, which provides insights regarding products and customer experience and helps to increase conversion rates per item and customer. For example, it identifies products that are more frequently picked up for try-on or left in the fitting rooms without being purchased. Fitting room technology also enables personalized customer experience by communicating with sales associates to bring products in different styles, sizes, or colors into the fitting rooms. Smart fitting rooms in collaboration with RFID tags, IoT technology, and in-store mobile apps enable omnichannel customer experience that offers both online and offline shopping benefits.

Other efforts have been made by retailers to offer personalized retail experience in physical stores. An example of such technologies is mobile computer vision coupled with augmented reality (AR) [5], which brings more flexibility for employees and customers in performing specific tasks. For example, shopping preferences of customers vary depending on their shopping goals and habits. Some customers enjoy spending time to browse and compare products while others just want to find what they want or find the best deals and complete shopping as quickly as possible. This computer vision AR technology helps customers with different needs by assisting those who want to find the exact product in a timely manner or those who need further information such as customer reviews or matching items of the product they are interested in buying. In the same manner, sales associates can cater for varying customer needs with the mobile technology.

Without utilizing mobile devices, customers can also interact with a product through embedded sensing technology in retail stores [4]. This sensing technology only works when customers pick up a product. Researchers have suggested that touching increases the sense of product ownership, which increases customer willingness to purchase the item and pay higher prices due to the endowment effect [6]. Several selected products are located in front of a computer screen. As a customer picks up and interacts with a specific product, the computer screen automatically provides more detailed information about the product with intriguing graphics and presentation. Examples of retailers who have been utilizing this technology include Macy's, Kate Spade, Neiman Marcus, and Sephora to name a few.

\section{Bridging in-store shopping benefits to online customer experience}

Many major brick-and-mortar stores have adopted advanced in-store technologies to offer convenience and informative shopping experiences that online shopping could only offer before those technologies became available. Despite its own shopping benefits, e-commerce has also struggled with high return rates associated with fitting issues and unavailable haptic information. Online retailers have had to create ways to increase online shoppers' buying confidence. Product reviews, fit ratings, and post-consumption reports are examples of e-commerce tactics to encourage online purchases and overcome major drawbacks of online shopping experiences. Amazon's Prime Wardrobe is another example that relieves buyers' stress and uncertainties during the purchase process. Prime users are allowed to order three to eight items and pay only for the products that work for them. They can return the rest without being charged for the unwanted items. 
True Fit is one of the key technology companies that assist retailers with its genome data. The Fashion GenomeTM organizes comprehensive industry data into product insights. This genome technology provides more accurate style, fit, and size information on the product description page of a product through the process of analyzing and integrating millions of garment specifications, style attributes, shopper information, and transaction data. True Fit has been collaborating with hundreds of retailers and brands for data collection and execution. Some of its retail clients include Macy's, Levi's, Kohl's, and DSW, and their brand data partners are Adidas, Calvin Klein, Hudson, Levi's, Helmut Lang, and so forth. 3D virtual try-ons are similar in the manner that it increases consumer buying confidence before they make a purchase decision online. Other technology companies have made efforts to offer haptic or sensory information for online customers. For example, Bonobos applied a certain degree of vibration on the image of a product in order for consumers to feel the fabric when they place their fingertip on the touchscreen. Although it is in the development stage, digital scent technology could allow consumers to smell fragrances of a product at home. Fragrance could be delivered in digital format via electrode-studded glasses or goggles as a way of virtual reality or augmented reality [7]. In the future, consumers may be able to smell fragrance when they shop for perfumes or candles without going to physical stores.

\section{Conclusion}

Retail technologies significantly affect the process of omnichannel retailing. Providing omnichannel shopping experiences is notan easy task. It requiresinvestment in technologies and cultural and operational changes within organizations. A true omnichannel retailer offers a seamless shopping environment through a connected and sophisticated platform in which customers do not distinguish differences whether they shop at brick-andmortar stores or their websites. Physical stores of a retailer should incorporate in-store technologies to offer unique customer experiences along with online shopping benefits. Its website should also help customers to increase the level of product certainties and buying confidence. Consumers increasingly shop across different channels to complete one transaction. These two channels should be seamlessly connected in a manner so that customers feel they are shopping at one store. This is the future of omnichannel retail.

\section{Acknowledgement}

None.

\section{Conflict of Interest}

Authors declare no conflict of interest.

\section{References}

1. Russell S, Norvig P (2016) Artificial intelligence: A modern approach. $\left(3^{\text {rd }}\right.$ edn), England Pearson, UK.

2. New Store (2019) Omnichannel Leadership Report 2019-2020.

3. CB4 (nd) Sophisticated (but Simple) AI for Next-Level Retail Execution. Power of AI.

4. Perch (nd) Perch platform.

5. Scandit (nd) Augmented Reality (AR) overlay.

6. Brasel SA, Gips J (2014) Tablets, touchscreens, and touchpads: How varying touch interfaces trigger psychological ownership and endowment. Journal of Consumer Psychology 24(2): 226-233.

7. Wynne P (2018) 'Digital smell' technology could let us transmit odors in online chats. 